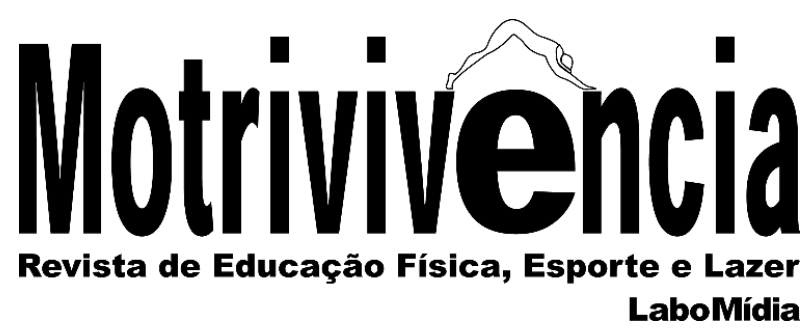

\title{
Luta Marajoara: lugar ou não lugar no currículo de uma IES pública do estado do Pará
}

\section{RESUMO}

Este artigo objetivou entender o lugar da Luta Marajoara no currículo de licenciatura em Educação Física de uma Instituição de Ensino Superior (IES) pública da região norte do Brasil. Realizou-se pesquisa de campo a partir de entrevista semiestruturada direcionada a dois docentes ministrantes do conteúdo Lutas, além de grupo focal com estudantes concluintes. Os resultados revelaram que a Luta Marajoara possui lugar implícito no currículo e ausente nas práticas de ensino do curso em questão. Concluiu-se que esta prática corporal, de identidade brasileira e marajoara, não consegue se legitimar no currículo da formação inicial em Educação Física, resultado da marginalização de seu conhecimento.

PALAVRAS-CHAVE: Luta marajoara; Educação física; Formação de professores

\section{Carlos Afonso Ferreira dos Santos}

Mestrando em Educação

Universidade Federal do Pará - UFPA

Núcleo de Estudos Transdisciplinares em Educação Básica Belém, Pará, Brasil afonso.fersantos@gmail.com ${ }^{(0)}$ https://orcid.org/0000-0003-4008$\underline{5478}$

Ivan Carlo Rego Gomes

Mestrando em Educação Universidade Federal do Pará - UFPA Núcleo de Estudos Transdisciplinares em Educação Básica Belém, Pará, Brasil ivanuepa@hotmail.com http://lattes.cnpq.br/3610780270604352

Rogério Gonçalves de Freitas

Doutor em Sociologia Universidade Federal do Pará - UFPA Belém, Pará, Brasil rogeriogf@ufpa.br

http://lattes.cnpq.br/5898521089584134 


\begin{abstract}
This article aims to understand the place of Marajoara Fight in the Physical Education undergraduate curriculum of a public Higher Education Institution (HEI) in northern Brazil. A field research was conducted from an interview with a semi-structured directed to two teachers teaching the Fight content, as well as a focus group with graduating students. The results revealed that Marajoara Fight has an implicit place in the curriculum and is absent in the teaching practices of the course in question. It was concluded that this body practice, of Brazilian and Marajoara identity, cannot legitimize itself in the curriculum of the initial formation in Physical Education, result of the marginalization of it knowledge.
\end{abstract}

KEYWORDS: Marajoara fight; Physical education; Teacher training

\title{
Lucha Marajoara: lugar o no lugar en el currículo de una IES pública del estado de Pará
}

\section{RESUMEN}

Este artículo buscó entender el lugar de la Lucha Marajoara en el currículo de licenciatura en Educación Física de una Institución de Enseñanza Superior (IES) pública de la región norte de Brasil. Se realizó investigación de campo a partir de entrevista semiestructurada a dos docentes quien ministra el contenido luchas, además de grupo focal con estudiantes concluyentes. Los resultados revelaron que la Lucha Marajoara tiene un lugar implícito en el currículo y ausente en las prácticas de enseñanza del curso en cuestión. Se concluyó que esta práctica corporal, de identidad brasileña y marajoara, no lo consigue legitimarse en el currículo de la formación inicial en Educación Física, resultado de la marginación de su conocimiento.

PALABRAS-CLAVE: Lucha marajoara; Educación física; Formación de professores 


\section{INTRODUÇÃO}

"Pés casados". Iniciem a luta...". E assim mergulhamos na trama ritualística e simbólica da Luta Marajoara. Prática socialmente referenciada, historicamente constituída, desenvolvida pelas populações locais e transmitida de geração em geração, com seus eventos, admiradores, fomentadores, praticantes e espectadores.

$\mathrm{Na}$ cotidianidade marajoara, a luta que tem no complemento de seu nome a marca geográfica da região destaca-se por ser uma prática corporal desenvolvida nos espaços mais singulares possíveis: praias, campos fazendas... É nesse território que simpatizantes da Luta Marajoara "lutam" para ter reconhecida essa prática que, durante anos, simboliza como um dos costumes do povo deste arquipélago no norte do Brasil.

A associação metafórica do "pé casado" na trama ritualística da Luta Marajoara representa, para nossos propósitos teóricos, uma aliança firmada entre sujeitos conterrâneos e simpatizantes em prol do reconhecimento local e nacional dessa luta brasileira. É nesse contexto de esquecimento da Luta Marajoara como prática corporal histórica que propomos suscitar reflexões a partir deste artigo.

Na perspectiva sinalizada, segundo Santos e Freitas (2018), a Luta Marajoara resulta do encadeamento de criação e recriação de elementos socioculturais por negros africanos e índios, mediante o entrelaçamento de suas experiências e saberes ocorridos em solos marajoaras. Difundiuse de geração em geração durante a história dessa região expressando tradição, criação e presença até os tempos mais atuais no Marajó.

A quase inexistência de elaborações teóricas e históricas sobre a Luta Marajoara nos impede de datar com exatidão sua gênese, a qual mais provável, de acordo com Santos e Freitas (2018), ao analisarem Salles (2004), entre os séculos XVIII e XIX no Pará. Neste último século, a visualização de sua prática por negros, vaqueiros e mulatos nos campos marajoaras coincide com os eventos do movimento da Cabanagem ocorridos no estado.

Luta brasileira, a Luta Marajoara é percebida nas experiências de Cruz (1987) ao observá-la em terras marajoaras e ter relatadas a sua tradição e prática por conterrâneos da região, destacando sua semelhança com o "sumô", estilo característico de luta no tocante à agarrada. Ademais, ao notar seu caráter ritualístico pela visualização da luta e seu desenvolvimento entre dois amigos marajoaras.

\footnotetext{
${ }^{1}$ Representa, na prática da Luta Marajoara, um rito que demarca o início da luta. "Pé casado", em sentido prático e simbólico compreende a posição inicial dos lutadores, os quais, de pés juntos, aguardam o sinal para o início do combate.
} 
Seu aspecto sociocultural, conforme Santos e Freitas (2018), enraíza-se nas tradições, hábitos e costumes historicamente presentes no arquipélago do Marajó. Suas técnicas tradicionais, estilo de luta, bem como características remontam às especificidades (sociais ou culturais) produzidas e desenvolvidas pelo povo marajoara. Basta, para isto, atentarmos à característica fundante de seu estilo de embate corpo a corpo entre sujeitos praticantes, o qual tem por referência os confrontos entre búfalos nos campos da região².

Em que pese o caráter sociocultural, simbólico, ritualístico e de tradição da Luta Marajoara, os quais estão intrinsecamente ligados aos objetivos da Educação Física, destaca-se que sua prática vem sucumbindo ao esquecimento nos espaços sociais educativos, a exemplo da escola (SANTOS; FREITAS, 2018).

Esta evidência reporta a necessidade de reconhecimento dessa luta e sua difusão nos espaços sociais e instituições formativas, como a formação inicial na educação superior. Nessa direção, essa pesquisa objetivou discutir se e como a Luta Marajoara pode se apresentar no currículo de formação da licenciatura em Educação Física de uma IES pública do estado do Pará. Além disso, procurou refletir as percepções de docentes e discentes do curso acerca deste conteúdo.

\section{MÉTODOS}

Trata-se de pesquisa de campo de abordagem qualitativa, acrescida de análise documental. Para a investigação em campo foi escolhida uma universidade pública da região norte do Brasil. Para a coleta dos dados foram selecionados docentes e discentes do curso de licenciatura em Educação Física desta instituição.

Com os sujeitos, fez-se uso de entrevista semiestruturada e grupo focal. O primeiro instrumento de coleta de dados foi utilizado com 02 (dois) docentes ministrantes da disciplina que trata das Lutas $^{3}$ na instituição investigada. O segundo, por sua vez, com uma turma em fase de conclusão de curso (discentes do $6^{\circ}$ semestre) que já teve contato com a disciplina. A todos os sujeitos foram entregues Termo de Consentimento Livre e Esclarecido (TCLE), o qual continha o objetivo e os detalhes da pesquisa.

No processo de coleta de dados, os questionamentos levantados junto aos docentes objetivaram investigar suas percepções, bem como suas propostas de trabalho docente em torno das

\footnotetext{
2 Esse aspecto sociocultural, construído no imaginário marajoara explica que uma possível inspiração para o desenvolvimento da Luta Marajoara se deu pela visualização dos confrontos (chifre a chifre) entre os búfalos nos campos marajoaras. Esta observação transferiu para a luta suas características principais no que tange ao embate corpo a corpo, tal como a "luta" dos ditos animais. Recomendamos o acesso a uma interessante reportagem feita sobre a Luta Marajoara por uma emissora nacional. Ver em: http://recordtv.r7.com/jornal-da-record/videos/embates-entre-bufalosinspiram-luta-marajoara-conheca-06102018.

${ }^{3}$ Entendida como conteúdo na Educação Física, terá, neste artigo, sua inicial maiúscula.
} 
Lutas e da Luta Marajoara. Com os discentes no grupo focal, a preocupação esteve nas percepções e conhecimentos em relação ao conteúdo Lutas e a Luta Marajoara. Além disso, investigou-se como as experiências de ensino oferecidas pelo curso, a partir do currículo, contribuíram para a instrumentalização dos discentes com este conteúdo. Para Morgan (1997), o grupo focal consiste em uma técnica de pesquisa qualitativa, baseada na coleta de dados por intermédio da interação entre um grupo de sujeitos selecionados.

Para a realização dessa etapa investigativa, procedemos à entrega de ofício junto ao protocolo da instituição para sua formalização. Foi também realizada ida a campo para contato informal com um docente ${ }^{4}$ do curso, com o objetivo de pedir-lhe abertura para a coleta de dados com os estudantes de sua disciplina, no início ou final de uma de suas aulas. No dia marcado para coleta, no qual compareceram 12 alunos, foram explicados os procedimentos, objetivos e detalhes da entrevista do tipo grupo focal, de modo a deixá-los inteirados de como ocorreria o processo. Posto isso, procedeu-se a entrevista e, consequentemente, a coleta das informações requeridas.

A análise documental empreendida compreendeu a análise hermenêutica de documentos que versam sobre pontos intrínsecos a nossa discussão neste artigo: a) o Projeto Político Pedagógico (PPP) da instituição e a estrutura curricular da disciplina "Fundamentos e Métodos das Lutas"; b) a Base Nacional Comum Curricular (BNCC), com vista à discussão característica da unidade temática "Lutas" no campo escolar da Educação Física; e c) as recém-homologadas Diretrizes Curriculares Nacionais do curso de graduação em Educação Física (DCNEF), as quais tratam das novas tendências para a formação inicial da Educação Física brasileira. A escolha pela análise deste último documento tem associação com a recente deliberação nacional regulatória de separação da formação entre licenciatura e bacharelado 5 .

A técnica de análise dos dados compreendeu a triangulação das distintas fontes investigadas na pesquisa (MARCONDES; BRISOLA, 2014), sendo elas o PPP do curso, a entrevista com docentes e grupo focal com discentes. Essa atitude metodológica permitiu o desvelar (construçãosíntese) do lugar da Luta Marajoara no currículo do curso, a partir da análise da ementa da disciplina "Fundamentos e Métodos das Lutas", em diálogo com os discursos dos sujeitos (análise contextualizada e triangulada dos dados). Assim, buscou-se compreender se a Luta Marajoara apresenta-se ou não no currículo e nas ações de ensino dos professores da instituição para, em seguida, explicitar as implicações de seu lugar ou não lugar.

\footnotetext{
${ }^{4} \mathrm{O}$ referido docente não participou como sujeito da pesquisa. $\mathrm{O}$ contato com o mesmo se deu unicamente para o fim almejado.

${ }^{5}$ Ressalta-se que, até o momento da pesquisa, o curso em questão oferecia apenas a modalidade de licenciatura.
} 


\title{
RESULTADOS E DISCUSSÃO
}

\section{O lugar das lutas e da Luta Marajoara nas recentes DCNEF e na BNCC}

As DCNEF (Parecer CNE/CES n ${ }^{0}$ 584, de 3 de outubro de 2018) apresentam a orientação quanto a formação do graduado em Educação Física nas IES públicas e privadas, entendendo, em seu Art. $3^{\circ}$, que

\begin{abstract}
A Educação Física é uma área de conhecimento e de intervenção profissional que tem como objeto de estudo e de aplicação a motricidade ou movimento humano, a cultura do movimento corporal, com foco nas diferentes formas e modalidades do exercício físico, da ginástica, do jogo, do esporte, das lutas e da dança, visando atender às necessidades sociais no campo da saúde, da educação e da formação, da cultura, do alto rendimento esportivo e do lazer (BRASIL, 2018b, p.7).
\end{abstract}

Conforme seu Art. $3^{\circ}$, a Educação Física representa área de conhecimento e intervenção que se vale do trabalho com práticas corporais em diferentes campos de atuação. Este trabalho, a partir das DCNEF, decorre da apropriação teórico-prática de conhecimentos, habilidades e atitudes que terá o graduando no campo formativo da Educação Física, seja na licenciatura ou bacharelado.

Nessa perspectiva, o capítulo IV das DCNEF desloca nosso olhar para a premissa supracitada, ao definir o bacharelado como formação voltada a três campos: saúde, esporte, cultura e lazer. Tais campos são definidores da formação e intervenção do bacharel no que diz respeito à prática profissional em treinamento esportivo, orientação de atividades físicas, preparação física, lazer, entre outros.

Por sua vez, a licenciatura (capítulo III das DCNEF), configura-se como campo de formação voltada a intervenção profissional na Educação Básica. Nesse cenário, observa-se que as Lutas, como objeto de conhecimento na Educação Física, é parte integrante da formação em licenciatura e, portanto, conteúdo na Educação Física escolar (BRASIL, 1997; BRASIL, 2018a; DARIDO, RANGEL, 2005). Pode-se dizer que seu trato na formação acadêmica pode estar atrelado aos pressupostos pedagógicos, culturais e metodológicos norteadores do trabalho pedagógico na escola.

A breve distinção entre os dois campos de formação a partir das DCNEF permite tecer duas conclusões prévias, ao passo que óbvias, e merecedoras de atenção crítica quanto à discussão em relação à separação do curso em dois segmentos formativos ${ }^{6}$ : a licenciatura se volta ao campo

\footnotetext{
${ }^{6}$ Nossa crítica se coaduna à visão de Iora, Souza e Prietto (2017) ao observarem, junto a egressos em Educação Física, que a fragmentação da formação implica, sobretudo, dois empecilhos: na negação do conhecimento gerado pela divisão, que reflete no distanciamento de ambos os cursos da realidade concreta, e na restrição do campo de atuação.
} 
educativo da escola básica, enquanto que o bacharelado se ancora a atuações profissionais em espaços que não a escola, a exemplo do alto rendimento esportivo (RUFINO; DARIDO, 2015).

No que concerne a Luta Marajoara, observa-se nesta luta, nas escolas do país, um importante potencial educacional e social, pois se caracteriza como prática originalmente brasileira. Além disso, carrega intrinsecamente vários elementos da cultura do Brasil, dos povos originários, da formação territorial, econômica e social, remontando às raízes e legados que a pluralidade do povo brasileiro desenvolveu. É uma prática que surge como modalidade moderna e de lazer, podendo ser abordada academicamente na Educação Física (licenciatura ou bacharelado) a partir de distintas vertentes, tais como história e cultura, técnicas, fundamentos básicos e relação com os esportes de combate competitivos.

Quanto ao segmento específico da formação em Educação Física voltado ao trabalho com práticas corporais na educação básica, figura como central o diálogo sobre o trato com o conhecimento da Luta Marajoara na escola a partir de documentos norteadores dos currículos brasileiros, tal como a $\mathrm{BNCC}^{7}$. Nesse documento, visualiza-se a unidade temática Lutas como focalizadora das

[...] disputas corporais, nas quais os participantes empregam técnicas, táticas e estratégias específicas para imobilizar, desequilibrar, atingir ou excluir o oponente de um determinado espaço, combinando ações de ataque e defesa dirigidas ao corpo do adversário [...] (BRASIL, 2018a, p.218).

Nessa unidade são apresentados quatro objetos de conhecimento para o trato com as Lutas quanto à ocorrência social dessa prática corporal: 1) as Lutas do contexto comunitário e regional, 2) as Lutas de matriz indígena e africana, 3) as Lutas brasileiras (capoeira, huka-huka, luta marajoara etc.) e 4) as Lutas de diversos países do mundo (judô, aikido, jiu-jítsus, muay thai, boxe, chinese boxing, esgrima, kendo etc.) (BRASIL, 2018a, p.218).

Quanto aos ciclos para o trato com as Lutas, a proposta da BNCC define que do $3^{\circ}$ ao $5^{\circ}$ ano deva ser desenvolvida, nesta unidade, as Lutas do contexto comunitário e regional, bem como as de matriz indígena e africana; para os anos $6^{\circ}$ e $7^{\circ}$, as Lutas do Brasil; e para os anos $8^{\circ}$ e $9^{\circ}$, as Lutas do mundo. Sobre a Luta Marajoara, ainda que esteja localizada na categoria das "Lutas brasileiras" na BNCC, faz-se imperativo o reconhecimento também de seu alinhamento à categoria de luta

\footnotetext{
${ }^{7}$ A BNCC é o documento que define as aprendizagens que todos os alunos do Brasil devem desenvolver em cada etapa da Educação Básica.

${ }^{8}$ É digno de nota a lembrança ao Brazilian Jiu-Jítsu, prática difundida e ensinada originalmente no Brasil, conforme relata Gurgel (2007) ao apresentar um breve histórico sobre a difusão dessa modalidade de luta em Belém do Pará, cidade paraense, no início do século XX.
} 
regional, a partir da reafirmação de sua identidade não somente brasileira, mas, especialmente, marajoara (luta do contexto regional norte-brasileiro - marajoara).

Os educadores, ao desenvolverem a Luta Marajoara nas aulas de Educação Física, necessitam ter em vista o desenvolvimento de habilidades relacionadas ao conteúdo Lutas na BNCC, tendo em vista, nos diferentes ciclos escolares, estarem citadas dimensões do conhecimento a serem privilegiadas no conteúdo, como: experimentação, usufruto e apropriação da prática corporal trabalhada, entre outras (BRASIL, 2018a). No que compete à especificidade de conhecer a Luta Marajoara na escola, bem como de vivenciá-la, possibilita ao estudante condições de realizar sua prática de forma autônoma pela apropriação do conhecimento novo intrínseco a esta modalidade de luta.

Desse modo, a partir da BNCC, a Luta Marajoara pode ser desenvolvida como conhecimento intrinsecamente ligado ao campo escolar da Educação Física, juntamente com outras práticas do conteúdo Lutas. Ademais, seu desenvolvimento, fora da escola, pode envolver diversos segmentos de prática, tais como festivais, espaços e momentos de lazer (SANTOS; FREITAS, 2018), academias e competições de esporte de combate?

Acreditamos que competem, nesse sentido, aos dois campos da formação (licenciatura e bacharelado) perspectivar essa luta em seus currículos e ações de ensino, ambos com suas especificidades de intervenção profissional. Haja vista a Luta Marajoara se situar como modalidade em luta que visa atender as necessidades sociais de diversos campos, entre eles o da educação, cultura, rendimento ou lazer, conforme explicitado no Art. $3^{\circ}$ das DCNEF. Reside nisto seu “possível” lugar nesta diretriz e, consequentemente, na formação inicial em Educação Física.

Refletidas as considerações provenientes da análise das DCNEF em Educação Física e sua relação com a Luta Marajoara, a seção seguinte de discussão centra o diálogo na configuração formativa voltada a licenciatura de uma universidade pública do norte do Brasil. Nossa intenção com a escolha da referida instituição concentra-se no lançamento de olhar ao currículo do curso de Educação Física desta universidade, de modo a responder o seguinte questionamento: possui lugar a Luta Marajoara nesse currículo?

\footnotetext{
9 “Terra de Luta" (episódio que integra a série documental "Espírito da Luta", realizada pela Academia de Filmes em parceria com o UFC e o Canal Combate) é um documentário que se propõe a apresentar lutas originárias brasileiras, dentre elas, a Luta Marajoara. Neste, registra torneio esportivo de combate da Luta Marajoara realizado na cidade de Soure-Marajó. Informações sobre a série disponível em: https:/www.ufc.com.br/news/combate-ufcr-e-academia-defilmes-lancam-serie-documental-espirito-da-luta.
} 


\section{Um diálogo introdutório sobre o lugar da Luta Marajoara: o currículo de uma IES pública do norte do Brasil}

A discussão curricular travada nessa seção reflete a análise sobre o currículo no processo formativo da licenciatura em Educação Física. Imerso nesse contexto, encontra-se a análise da Luta Marajoara como conhecimento em potencial nos conteúdos programáticos de propostas formativas curriculares deste curso no Brasil e, em especial, no Estado do Pará.

Segundo Sacristán (2000), o currículo e suas funções expressam-se em um projeto de cultura manifestado em conteúdos, formato e práticas criadas em seu entorno. Advém desta noção a necessidade de destaque a este dispositivo e sua centralidade no interior dos contextos nos quais ganha forma, seja no espaço escolar ou nos processos de formação a nível superior. Resulta disto, para o autor, o desvelar do currículo como elemento que garante, em contexto determinado, o alcance a práticas educativas.

Em paralelo ao sentido empregado no que concerne ao currículo por Sacristán (2000), tornase eminente a reflexão desse objeto a partir do contexto em que foi produzido (PACHECO, 1996), tendo em vista essa evidência compreender um diálogo comum entre os autores, ao acreditarem que o currículo se rege baseado nos interesses de seus interlocutores. Isso explica, por exemplo, a tese de Silva (2006), sobre a qual confere ao currículo uma prática de significação, refletida na política curricular enquanto discurso e elemento simbólico do projeto daqueles que possuem o poder de prescrever seu texto (conteúdo).

No contexto das ideias apresentadas por Sacristán (2000) e Pacheco (1996), o currículo de educação superior apresenta um projeto de formação. Sua constituição apela para discursos (modos textuais) que materializam práticas voltadas à formação profissional nas determinadas áreas do conhecimento, reconhecida a necessidade deste currículo não prezar pela listagem exaustiva de conteúdos de ensino, que por sua vez necessitam estar agrupados em campos de estudo amplos, conforme alertado nas Diretrizes Curriculares para os Cursos de Graduação, documento produzido no Fórum de Pró-Reitores de Graduação das Universidades Brasileiras - ForGrad (BRASIL, 2000).

$\mathrm{Na}$ perspectiva sinalizada acima, reside a análise do conhecimento da Luta Marajoara no currículo de Educação Física da universidade lócus desta pesquisa, especialmente no que confere a problemática de seu lugar no projeto político e pedagógico da instituição. Para a análise teóricodocumental dessa problemática, empreendeu-se investigação na ementa da disciplina "Fundamentos e Métodos das Lutas", situada no desenho curricular do PPP do curso. A referida disciplina integra o conjunto de componentes curriculares do sexto semestre da formação, abarcando em sua ementa a 
Ênfase às lutas mais expressivas na cultura brasileira, raízes históricas, evolução e a análise crítica do processo de esportivização. Conhecimento dos fundamentos técnicos e análise das regras básicas das lutas. Possibilita a práxis pedagógica crítico-reflexiva e investigativa tomando as lutas como referência. Organização de eventos lúdico-esportivos (CURSO DE EDUCAÇÃO FÍSICA, 2007, p.95).

Como observado, o currículo para as Lutas, articulado às prerrogativas do ForGrad, não abrange a disposição de conteúdos e tópicos específicos em Lutas (ou seja, exposição de diversas modalidades de lutas a serem trabalhadas na formação acadêmica). Contrariamente, o mesmo currículo busca tratar desta prática com referência a abrangência de seu campo. Assim, possui como norte o trabalho com lutas expressivas, processos históricos, fundamentos, regras básicas etc.

Assim observado, em um primeiro olhar, ainda fenomênico, ressalta-se a não disposição de conteúdos específicos (Lutas) no currículo do curso investigado. Essa perspectiva somente é assumida pela bibliografia da disciplina, a qual aponta referenciais específicos para o trato da capoeira, do judô e do karatê (CURSO DE EDUCAÇÃO FÍSICA, 2007). Assim sendo, relaciona-se a oferta bibliográfica de referência da instituição em seu texto prescrito.

Em premissa secundária, destaca-se que a Luta Marajoara, possivelmente em função da pouca exploração acadêmico-científica de seu campo, expressa-se em ausência no referencial bibliográfico do currículo do curso. Seu reconhecimento assume destaque somente do ponto de vista da configuração da ementa, a qual admite a "ênfase às lutas expressivas na cultura brasileira" (CURSO DE EDUCAÇÃO FÍSICA, 2007, p.95).

A Luta Marajoara, entendida como prática corporal e, portanto, conhecimento na Educação Física escolar, reflete a premissa evidenciada por Correia (2016) ao salientar que a legitimação desse componente curricular se dá a partir da relevância social de seus conteúdos. Tomada sua contemplação no conteúdo Lutas, a Luta Marajoara reúne elementos de conhecimentos relevantes para serem aprofundadas no espaço escolar. Assim como, em função de sua relevância social, manifesta prática a ser explorada em outros âmbitos de educação, que não a escola.

Dessa maneira, os pontos refletidos caracterizam a necessidade do conhecimento da Luta Marajoara se apresentar nas dinâmicas curriculares (oficiais ou em ação) da formação docente em Educação Física. Todavia, como pudemos observar, essa prática compreende um lugar implícito no currículo e projeto formativo voltado às Lutas do curso investigado.

Em função disto, com vista ao desenvolvimento de análises mais aprofundadas com relação a problemática do lugar da Luta Marajoara nas ações curriculares da formação inicial em Educação Física, as seções seguintes constituem pontos de relevância, uma vez que traduzem as vozes, discursos e anseios de sujeitos (docentes e discentes) imersos diretamente nas experiências 
formativas do curso de licenciatura em Educação Física de uma universidade estadual pública da região norte do Brasil.

A necessidade de escutar tais sujeitos representou o movimento de reflexão sobre o real ${ }^{10}$ lugar que o conhecimento da Luta Marajoara compreende na formação do campo. Com isso, buscamos imergir no próprio currículo vivido da instituição a partir de suas falas. Tal necessidade revela-nos, assim, uma entre duas possibilidades: 1) a não legitimação dessa prática no currículo do curso, ou 2) a resistência de tais sujeitos a seus ordenamentos, com ênfase na materialização de práticas acadêmicas e formativas com a luta.

\section{Vozes de dentro e olhar docente}

Esta seção de discussão apresenta os resultados produzidos por meio de entrevista realizada com dois docentes, os quais denominaremos Prof. 01 e Prof. 02. Ambos ministram o conteúdo "Fundamentos e Métodos das Lutas" no curso de Licenciatura em Educação Física de uma IES pública no norte do Brasil (Amazônia brasileira). Além de graduados em Educação Física, os professores, do sexo masculino, possuem especialização em treinamento desportivo e são os únicos docentes responsáveis pela disciplina na instituição. Posto isto, as questões com referência ao contato docente com o conteúdo Lutas na formação em Educação Física objetivou diagnosticar pontos para o entendimento de como seu conhecimento vem sendo tratado nas práticas de ensino do curso.

Inicialmente, perguntou-se aos docentes sobre o tempo que ministram o conteúdo "Lutas". Essa questão revelou elementos relevantes para um olhar direcionado a história de trabalho docente dos sujeitos com as Lutas no curso da instituição de ensino superior onde atuam.

Verificou-se que ambos trabalham na instituição e ministram o conteúdo ${ }^{11}$ há mais de trinta anos, o que representa uma longa carreira. A extensa história docente dos dois sujeitos representa ponto chave para a compreensão da construção de suas identidades como professores. Noção essa que implica, por sua vez, na construção de atitudes e ações refletidas no interior de seu trabalho docente. De acordo com Pimenta (1999), os saberes da docência mediados pela experiência produzem no cotidiano dos professores um processo permanente de reflexão sobre a prática, bem como o desenvolvimento de habilidades voltadas a seu trabalho.

\footnotetext{
${ }^{10}$ Por "real" nos referimos ao currículo em ação (SACRISTÁN, 2000). O currículo em ação expressa as práticas educativas realizadas no cotidiano de determinadas instituições, como a escola e a universidade.

${ }^{11}$ Nota-se a presença da disciplina que trata das Lutas na instituição antes mesmo da década de 80 , tendo em vista a fala dos docentes reportarem sua inserção no currículo desde suas entradas na instituição: o Prof. 01 em 1980 e o Prof. 02 em 1982; além da lembrança do Prof. 01 sobre o contato com a disciplina quando ainda acadêmico em Educação Física, portanto, anterior a dita década.
} 
Os questionamentos seguintes buscaram entender qual relevância os professores atribuem ao conteúdo Lutas na formação inicial e, consequentemente, quais objetivos almejam com seu trabalho, em paralelo ao PPP do curso e sua atual configuração formativa na instituição (licenciatura).

Revelou-se que os principais objetivos dos docentes com as Lutas são "Pedagógico/escolar", os quais convergem com os objetivos da formação em licenciatura do curso de Educação Física da instituição e das Diretrizes Curriculares Nacionais para a formação inicial em nível superior dos cursos de licenciatura (BRASIL, 2015). Esse diagnóstico, porém, não descarta a possibilidade de formação ampliada com ênfase no trabalho voltado a outros campos de atuação. Isso se evidencia no discurso de um dos docentes, ao reconhecer o curso como campo de formação voltado a atuação na educação básica, porém com abrangência para outros campos educativos. Sua preocupação enquanto docente se concentra no trabalho didático-pedagógico com noções básicas das Lutas, intencionando a apropriação dessas por seus alunos e possível articulação com seu futuro fazer profissional, seja em escolas, academias ou outros espaços.

O conjunto de questões sobre as Lutas possibilitou ainda a análise sobre quais lutas do Brasil e do mundo os docentes já trabalharam ou trabalham na formação inicial em Educação Física. A questão objetivou o olhar para a seleção de conhecimentos que fazem os professores a partir do currículo, tendo em vista a variedade de lutas existentes em território nacional e mundial.

Os professores destacaram o trabalho com lutas prescritas na ementa da disciplina, localizada no currículo do curso, as quais temos capoeira, judô, karatê e boxe ${ }^{12}$. A tendência dos professores para o trabalho com lutas unicamente prescritas no currículo revela noção crítica acerca do que discute Arroyo (2011, p.16). Para o autor, o documento curricular figura como objeto no qual está disposta uma pluralidade de normas dirigidas aos profissionais que irão com ele se relacionar, afirmando-o como "ordenamentos disciplinados" e "corpos normatizantes" do trabalho profissional. Essa visão de currículo como veremos adiante, reflete, sobretudo, no lugar que a Luta Marajoara possui na proposta curricular para as Lutas do curso.

A partir da questão anterior, iniciou-se o segundo conjunto de questões, agora com referência à Luta Marajoara como conhecimento na formação docente em Educação Física. Procurou-se entender, com tais questões, qual visão os docentes possuem sobre essa luta. Corroborando Santos e Freitas (2018), o discurso docente revela a visão e relevância que atribuem

\footnotetext{
${ }^{12}$ Como já evidenciado, tais modalidades de luta foram selecionadas para estarem presentes na bibliografia de referência da disciplina "Fundamentos e Métodos das Lutas". Sua seleção, dentre várias outras lutas, decorre da reformulação curricular do PPP do curso ocorrida entre os anos de 2002 e 2007, a qual buscava orientar a política de formação de professores da área. $\mathrm{O}$ que se percebe, todavia, e especialmente no discurso prescritivo da disciplina investigada, foi a "preferência" por modalidades tradicionais de lutas pelos sujeitos elaboradores do currículo do curso, impossibilitando o alargamento de seu referencial bibliográfico para outras modalidades.
} 
acadêmica e profissionalmente a essa luta brasileira, a partir de uma concepção marcadamente cultural. Na visão do Prof. 01, a luta expressa a cultura do caboclo e povo marajoara, além de apontar que "[...] Culturalmente tem muita (relevância), tanto que até hoje se mantém a tradição em alguns interiores, que também já está bem mais fraca do que era 20, 30 anos passados”.

Tal como expressa no fim de sua fala anterior, a concepção cultural apontada pelo docente é carregada de um tom pessimista ao acreditar, ainda, na incerteza do futuro da luta e seu esquecimento: "Hoje o futuro dela é uma baita interrogação, caminhando para o esquecimento. Em universidade nunca chegou a ser ensinada [...]" (Prof. 01).

O Prof. 02, similarmente à ideia do Prof. 01, destaca a Luta Marajoara como patrimônio cultural do Marajó e símbolo identitário da região norte do Brasil ao reconhecer que é "uma luta nossa". Contudo, revela ainda não enxergar na luta relevância acadêmica, tendo em vista não se apresentar como conteúdo de ensino no currículo do curso no qual ministra a disciplina.

O dado supracitado suscita reflexão. Em perspectiva curricular, em vista do reflexo da ausência da Luta Marajoara no desenho do curso, revela vozes ausentadas do currículo quando sua estrutura, não dispõe de força e poder para se estabelecer como cultura selecionada (SANTOMÉ, 1995). Nesse contexto, a visão do Prof. 02 destaca um ciclo "vicioso" em torno da Luta Marajoara em função do currículo. Este ciclo pode ser mais bem compreendido a partir da figura 1 abaixo:

Figura 1 - Não atribuição de relevância acadêmica à Luta Marajoara, em virtude de sua ausência no currículo.

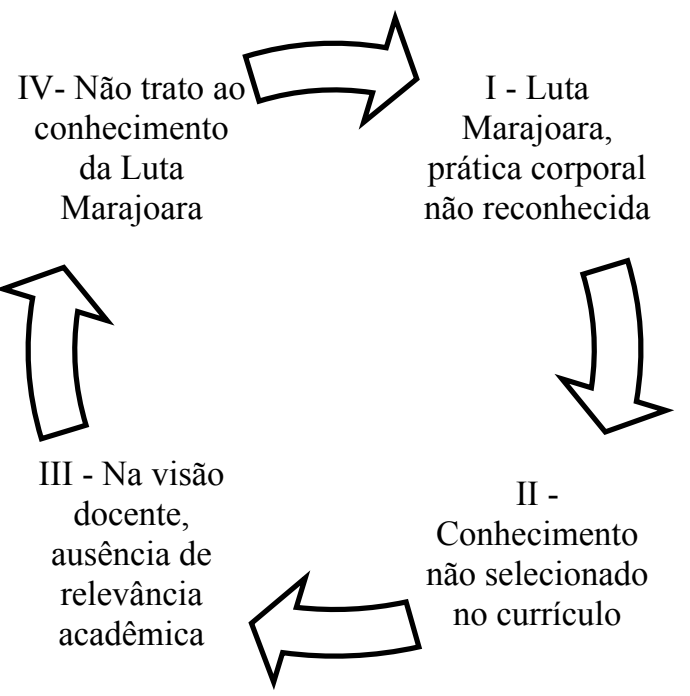

Fonte: Os autores, a partir das ideias de Santomé (1995).

O ciclo acima, em paralelo a tese de Santomé (1995), representa a não consolidação do conhecimento da Luta Marajoara no currículo da formação inicial em Educação Física, resultado do que podemos chamar de marginalização de sua prática e cultura na história e, portanto, na própria 
"cultura acadêmica" da Educação Física. Um paradoxo, pois, ao mesmo tempo em que se admite sua relevância cultural, padece de legitimação cultural no âmbito do currículo e da prática, o que explica a não seleção de seu conteúdo e, consequentemente, o trato de seu conhecimento.

Observada a reflexão anterior, as questões finais almejaram diagnosticar e refletir sobre o trabalho docente com a Luta Marajoara na disciplina que trata das Lutas na formação acadêmica do curso investigado.

Evidenciou-se que os dois docentes não trabalham ou nunca trabalharam o conhecimento da Luta Marajoara na formação em Educação Física, fato que implica na carência de sua apropriação teórico-prática pelos discentes no processo de formação e, nesse sentido, na tendência de aumento do índice de esquecimento dessa luta nos espaços de atuação profissional. Sobretudo na escola, como já demonstraram Santos e Freitas (2018) em um dos estudos pioneiros sobre a Luta Marajoara.

A ausência da Luta Marajoara nas práticas docentes de ensino, bem como no currículo do curso, ratifica seu não lugar na formação em Educação Física. Sobre isto, a justificativa central de ambos os docentes recai, inevitavelmente, na ausência dessa luta no desenho curricular do curso.

Em paralelo, um dos docentes destacou, em especial, a falta de condições para trazer alguém praticante da luta de modo a incluí-la como unidade em suas aulas. Entretanto, como podemos observar na literatura das Lutas no campo da Educação Física, a perspectiva assumida pelo professor somente revela uma percepção equivocada sobre a necessidade de vivências substanciais com algumas lutas em sua vida cotidiana (NASCIMENTO; ALMEIDA, 2007).

Em que pese este e outros fatos analisados, faz-se importante destacar nossa atitude reflexiva quanto à crítica aos docentes investigados. Eles carregam o peso de influências externas ou internas no entorno das contradições históricas do trabalho docente, seja no currículo, seja nas práticas quotidianas de ensino no curso. Dados que não nos permitem a atitude de culpabilização didática, teórica ou metodológica de ambos.

Destacada tal ressalva, a discussão seguinte sintetiza as vozes de discentes do curso de Educação Física sobre o contexto que abrange o ensino da Luta Marajoara na formação inicial. Elenca-se como discussão imprescindível, pois traduz os anseios de sujeitos centrais a quem se destina o conhecimento elaborado no ensino superior. Portanto, sujeitos que, pós-formação acadêmica materializarão práticas do campo de conhecimento da Educação Física. Tiveram, tais sujeitos, aporte suficiente para a materialização de práticas educativas com a Luta Marajoara? 


\section{Vozes de dentro e olhar discente}

Os questionamentos direcionados aos discentes, por meio do grupo focal, procuraram refletir suas visões acerca das Lutas e da Luta Marajoara no processo acadêmico e formativo em Educação Física, bem como levantar discussão sobre como o fenômeno Lutas e, especificamente, a Luta Marajoara foi abordado nesse mesmo processo ${ }^{13}$.

Quanto às questões referentes às Lutas, procurou-se entender qual aproximação dos discentes em caráter acadêmico ou pessoal. A pergunta teve caráter estimulador da discussão do grupo. Para além disso, teve por intenção diagnosticar a aproximação dos alunos com esta prática corporal, a partir do pressuposto da importância de sua presença no acervo do professor de Educação Física.

Os dados apreendidos no grupo focal revelaram que um número limitado de alunos pratica algum tipo de modalidade de luta. Somente dois sujeitos informaram que são praticantes de muay thai. Observou-se ainda que outros discentes mostram interesse em sua vivência prática, destacam conhecimentos relacionados às lutas, como as artes marciais, bem como as associa a expressão corporal somente:

Acho que depende muito da luta, tem lutas que são artes marciais, que tem uma história, uma tradição e as lutas que são só uma expressão corporal pela expressão corporal. Por exemplo, o boxe, o boxe não tem toda essa tradição, toda uma história por trás, como tem o karatê, por exemplo.

Destaca-se a necessidade, nesse relato, de não atribuir à expressão corporal um sentido equivocado e neutro de concepção (por exemplo, entender a "expressão corporal" interseccionada ao campo estético somente), pois com referência a proposta de Soares et al. (2012), a expressão corporal é uma linguagem dotada de sentido, significado e objetivos. Nessa assertiva, o boxe, igualmente ao karatê caracteriza-se como linguagem munida de tradição e de sentido sóciohistórico, não somente estético.

Outra questão centrou na observação discente sobre o fenômeno das Lutas na Educação Física. Partiu-se da visão atribuída às Lutas como prática corporal histórica do campo da Educação Física, produzida pelo homem na história da humanidade e, portanto, em relação intrínseca a seus objetivos. Nesse sentido, a questão buscou evidenciar a visão dos alunos sobre quais espaços as

\footnotetext{
${ }^{13} \mathrm{O}$ desenvolvimento do artigo até a presente etapa já mostrou que a Luta Marajoara está ausente no currículo do curso (na ementa da disciplina que trata das Lutas no PPP) e nas práticas de ensino dos docentes que ministram a disciplina "Fundamentos e Métodos das Lutas".
} 
lutas podem estar presentes, assim como quais objetivos são atribuídos a esse fenômeno, tendo em vista sua prática sinalizar para um campo vasto de objetivos, quer sejam pedagógicos, escolares, de treinamento, lazer etc.

Diante a indagação, porém, evidenciou-se dificuldade em responder de forma elaborada como devem ser abordadas as lutas ou quais objetivos possuem no contexto escolar ou não escolar, fato que alerta para a fragilidade teórica dos discentes com relação a esta prática corporal, como veremos adiante. Destaca-se como única resposta a essa questão: “Eu acho, pra mim, que é o mínimo de conhecimento ao redor das lutas, porque se um dia eu precisar vou ter que mostrar o que eu sei. [...] é o mínimo de conhecimento que eu vou levar pra minha aula de educação física".

Perguntou-se ainda aos discentes se o curso os instrumentalizava para uma atuação qualitativa com as Lutas. A importância deste questionamento reside no intuito de entender se um lócus específico de formação acadêmica em Educação Física, em região amazônica, vem conectando futuros professores ao domínio de conhecimentos e estratégias pedagógicas, metodológicas e de ensino em torno do campo das Lutas, bem como se abrange a variedade de objetivos atrelada a essa prática corporal.

Foi manifestado consenso que a disciplina ministrada dificultou, ao conjunto da turma, o desenvolvimento de atividades refletidas com as Lutas no contexto escolar ou não escolar. Dentre as muitas ponderações, sobressaíram-se a metodologia do professor, a carga horária da disciplina e a ementa do curso. Porém, o fator mais evidenciado foi a metodologia adotada e as atividades desenvolvidas, fortemente caracterizadas pela execução técnica e pela concepção tradicional no que se refere à relação entre professor e aluno ou, tal como historicamente no campo, à relação treinador-atleta (SOARES et al., 2012). Nesse ponto, os relatos foram vários:

$\mathrm{Na}$ minha opinião, a gente teve que aprender um pouco sobre a luta, mas eu acho que faltou voltar esse conhecimento pro meio escolar, não só pro meio escolar, mas se, por exemplo, tu quisesse dar aula em outro lugar, claro que tu não vai sair daqui formado em lutas, mas pelo menos ter uma base de como poderia passar pra alguém [...].

A gente era avaliado o quanto a gente tinha que saber praticar como se estivesse em uma academia de lutas, a gente não era avaliado em nossa didática, como dar uma aula, como fazer um combinado relacionado a uma determinada luta, aplicar em uma turma $[\ldots]$.

Faltou uma vivência da gente, como se a gente fosse professor. 
Foram afirmadas inúmeras vezes que faltaram orientações didáticas e metodológicas no sentido de formar para a prática pedagógica, para o ensino das Lutas nos ambientes de intervenção profissional. A metodologia utilizada, na visão dos discentes, seria inadequada, baseada em decorar, imitar e reproduzir o que foi transmitindo, sucumbindo os discentes ao esquecimento do conteúdo após o término das aulas. Conforme apontam, a proposta metodológica foi pouco relevante para a formação docente, tendo em vista a disciplina não proporcionar contributos teórico-práticos essenciais para o ensino dessa prática corporal na atuação profissional, impossibilitando-os, por consequência, a construção de sua identidade como professores em torno das Lutas.

A situação apresentada nos reporta a Freire (1996) ao refletir sobre o processo de ensino na prática educativa, intitulando no capítulo inicial de sua obra que não há docência sem discência, pois

Ensinar inexiste sem aprender e vice-versa e foi aprendendo socialmente que, historicamente, mulheres e homens perceberam que era possível - depois, preciso trabalhar maneiras, caminhos, métodos de ensinar. Aprender precedeu ensinar ou, em outras palavras, ensinar se diluía na experiência realmente fundante do aprender (FREIRE, 1996, p.26).

Além da ausência do processo de "ensinar a ensinar", a prática do professor da disciplina, apontada no grupo focal pelos alunos, evidencia uma concepção de Educação Física com ênfase no desempenho técnico na prática em Lutas, portanto em descompasso, inclusive, aos objetivos traçados no PPP e na própria ementa da disciplina. Reflete-se acerca disso uma concepção de Educação Física tradicional em perspectiva tecnicista calcada nos princípios da racionalidade, eficiência e produtividade (SOARES et al., 2012), há anos relegada à história passada do campo.

Em síntese, esta seção da entrevista, com ênfase nas percepções discentes acerca do fenômeno das Lutas, ficou marcada pela crítica quanto à concepção de Educação Física tradicional, uma abordagem tecnicista e a falta de didáticas que orientem a prática pedagógica: dilemas historicamente constantes no campo.

A seção final de análise dos resultados produzidos na pesquisa centrou-se na visão dos alunos sobre a Luta Marajoara. A importância dessa discussão é reveladora em dois pontos: a necessidade discente em compreender o fenômeno da Luta Marajoara como conhecimento intrínseco ao campo das Lutas e da Educação Física, e a relevância regional de visualizar nessa luta um conhecimento em potencial de ser tratado na atuação profissional em função de sua identidade brasileira, marajoara e amazônica.

Verificou-se que os alunos têm poucas referências da Luta Marajoara, mas em geral tem alguma informação, com destaque para o conhecimento de um atleta marajoara lutador no UFC ${ }^{14}, \mathrm{o}$ 
qual tem aparecido bastante na mídia nacional por seus excelentes desempenhos. A exceção são dois alunos oriundos da Ilha do Marajó que possuem a vivência da luta e citam sua prática em festivais e competições, tal como revelam Santos e Freitas (2018).

No que diz respeito à importância da Luta Marajoara, vários discentes ressaltaram a importância cultural e o papel social da Educação Física para a formação na Educação Básica quanto aos conhecimentos da cultura local e regional, sua valorização, reconhecimento e resgate, tal como as percepções dos docentes da disciplina. Relatam os alunos:

[...] Principalmente aqui na nossa região, porque a gente tem como relacionar a Educação Física e trazer ela pra algo que é nosso, é da nossa cultura.

É cultura. Até pra não deixar se perder, a questão histórica, pras novas gerações. O nosso papel como professor de Educação Física é trazer esse lado cultural. Existia uma disciplina de folclore que era optativa que meio que traz esse lado cultural. Que eu vejo como nosso papel.

Nesse sentido, a disciplina que evidencia os conhecimentos relacionados às Lutas, juntamente com outras disciplinas, foi ressaltada pela importância de abordar as questões culturais, a historicidade da região e das práticas corporais identitárias. A Educação Física, nesse sentido, constitui-se campo de conhecimento privilegiado com vista à evidência de tais discussões no ambiente escolar, vide BNCC (BRASIL, 2018a) e a perspectiva curricular da Educação Física cultural (NEIRA, 2017, 2018).

As questões finais propiciaram um olhar sobre o lugar, na visão dos alunos, do conhecimento da Luta Marajoara na formação inicial em Educação Física, de modo a realizar um paralelo entre o que apontam estes sujeitos e os discursos apresentados pelos docentes do curso. Mediante a pergunta "Acreditam que a formação na instituição lhes ofertaram conhecimento teórico e metodológico suficiente para a atuação com a Luta Marajoara?”, foi possível desvelar que não, o que também dialoga com os discursos dos docentes da disciplina.

Em consonância a esta discussão, apontamos a necessidade da formação docente em Educação Física sinalizar para o trato com determinados conhecimentos no contexto de formação para a docência, de modo a munir discentes em caráter teórico-prático, e construir sua identidade docente para a visualização dos objetivos formativos, sociais e culturais envoltos nos saberes produzidos pela história humana. A Luta Marajoara, como conhecimento local e global se atrela a essa perspectiva.

\footnotetext{
${ }^{14}$ Ver reportagem com o lutador e irmão, igualmente lutador, em sua terra de origem, apresentando e exibindo a Luta Marajoara: https://sportv.globo.com/site/combate/noticia/bufalos-turu-e-luta-iuri-e-ildemar-marajo-voltam-as-origensem-soure.ghtml.
} 
É importante, nesse sentido, considerar processos na formação docente, dentre as quais, para Nóvoa (1992), a produção da profissão docente. Na visão do autor, é imperativa a necessidade da formação docente investir de forma positiva nos saberes dos quais o professor é emissário, trabalhando tais saberes de forma teórica e conceitual. Nessa trama, a Luta Marajoara se elenca como saber na formação inicial em Educação Física carente, a partir do autor, de mobilização teórico-prática, pedagógica, reflexiva e investigativa.

Para efeito de diagnóstico final foi perguntado aos alunos se acreditam que estão saindo da formação inicial preparados para trabalhar com a Luta Marajoara na Educação Física. Os discursos acenam, de forma unânime, para uma negativa. Destacam-se os seguintes discursos:

Eu acho que pra gente poder levar algum conteúdo pra escola [...] pra qualquer meio, pra gente poder passar pra alguém, precisa pelo menos da vivência prática, porque como é que a gente vai ensinar outra pessoa a vivência prática se a gente não sabe nem pra gente mesmo? Então, não adianta, mesmo que a gente vá atrás, leia, a questão da historicidade [...] a gente não tem a prática, então de qualquer jeito a disciplina ficaria pela metade [...] no caso, com a questão da Luta Marajoara. Então, não teria como. Eu, particularmente, não teria como mostrar pro aluno a Luta Marajoara. A culpa é de quem? Nunca tive embasamento, nem na universidade $[\ldots]$.

É porque eu vejo assim também: o nosso curso ele é muito voltado pras práticas que a gente encontra na cidade e, tipo, a gente acaba ignorando essas práticas corporais que poderiam ser trabalhadas, principalmente as daqui, no caso, a Luta Marajoara, sabe. Se a gente tivesse recebido esse conteúdo, a gente estaria apto a trabalhar esses conteúdos na escola, o problema é que a gente não recebe aqui, esses conteúdos, tanto na luta, quanto nas danças, quanto qualquer outra prática corporal que seria necessário trabalhar nas escolas.

Esses discursos "denunciam" o currículo do curso, o qual orienta as práticas de ensino da disciplina de Lutas, bem como de outras disciplinas. Nessa perspectiva, a prática da Luta Marajoara não foi "trabalhada" porque estaria fora da ementa, estando as aulas concentradas principalmente no karatê $^{15}$ e timidamente no judô, boxe e capoeira. O segundo discurso é significativo, pois dialoga com o ciclo apresentado na figura 1 desta pesquisa, tendo em vista a percepção do aluno acerca de quais conhecimentos são privilegiados no currículo do curso. Destaca-se, com base nisso, a Luta Marajoara como conhecimento que não se enquadra nos tipos de lutas "encontradas na cidade", em função de sua identidade cultural e regional.

A situação em evidência alerta, em perspectiva curricular, para a necessidade de ampliação das práticas - especialmente regionais - no currículo do curso e nas ações de ensino dos professores para com o conhecimento das Lutas. Essa necessidade aponta, tal como alerta Darido (2003), para

\footnotetext{
${ }^{15}$ Face sua aderência exclusiva por um dos professores da disciplina.
} 
um campo de trabalho no qual se preze o afastamento a conteúdos hegemônicos na Educação Física escolar. Acerca disso, dois alunos comentam que:

\begin{abstract}
Mesmo não tendo na ementa a Luta Marajoara, o professor também poderia ter o bom senso de trazer assuntos daqui, lutas, vivências daqui da nossa região, sabendo que a gente poderia trabalhar em escola [...] isso acabaria estimulando até o (sujeito cita os alunos do Marajó presentes na turma) que são do interior. Poderia estimular eles a trabalhar isso nas aulas de Educação Física, quando eles forem professor.
\end{abstract}

O professor poderia estender, aumentar o leque de possibilidades.

É relatado pelos sujeitos que o trato a outros saberes na formação em Educação Física precisa ser viabilizado. Tais discursos ressaltam a necessidade de avanço em relação aos conteúdos prescritos no currículo corroboram as ideias de Arroyo (2011, p.46) ao apontar que o currículo é o território que, embora normatizado, é o mais politizado, inovado e ressignificado. Destaca a necessidade do currículo se ampliar na prática pela incorporação de temáticas, experiências sociais, propostas e criação própria do campo de trabalho. Tais atitudes (des)ritualizam o currículo e não o tornam mais um território “intocável e inevitável” no qual não se permite a "crítica, a desconstrução, o reordenamento".

\title{
CONCLUSÕES
}

Os dados analisados e produzidos na pesquisa permitiram a evidenciação de algumas considerações alcançadas. Inicialmente, conclui-se que a Luta Marajoara manifesta ausência - ao menos explicitamente - no currículo de Educação Física da IES investigada, localizada no norte do Brasil. Esse fato foi confirmado, tanto por docentes ministrantes da disciplina, os quais não tratam desta luta no currículo do curso, quanto por discentes. Os últimos apontaram as implicações do não trato da Luta Marajoara na formação acadêmica, quer sejam a não apropriação de conhecimentos regionais e a impossibilidade de seu trato educativo nos espaços de intervenção profíssional.

No que diz respeito aos achados junto aos docentes e discentes, evidenciou-se que suas visões com referência a ausência da Luta Marajoara no currículo e nas práticas de ensino são congruentes, ao passo que díspares. Em perspectiva curricular, essa disparidade se manifesta em uma tensão declarada. De um lado, docentes acolhedores dos ordenamentos prescritos no currículo do curso (na disciplina que trata das Lutas). De outro, alunos que sinalizam para o trato a um maior número de saberes, o qual passa por sua ampliação na prática e subversão aos ordenamentos do currículo. 
Posto esse quadro, as considerações finais deste artigo sinalizam alguns anseios. Primeiro, uma maior abordagem acadêmico-científica da Luta Marajoara, a qual pode ser fator decisivo para o reconhecimento dessa modalidade de luta nos currículos de ensino superior da Educação Física da região norte do país e de outras regiões brasileiras. Segundo, que a formação do campo evidencie uma diversidade de práticas, oportunizando a apropriação de um acervo maior e qualitativo de conhecimentos pelos alunos na construção de sua identidade docente. Por fim, que a Luta Marajoara seja reconhecida como conhecimento regional e nacional, dotada de objetivos formativos no campo educativo da Educação Física.

O último anseio em destaque decorre do fato da Luta Marajoara não vir conseguindo ocupar seu lugar no currículo da formação inicial em Educação Física, resultado da marginalização de seu conhecimento. Sinalizamos, portanto, a necessidade de valorização a essa prática corporal de identidade norte-brasileira nos currículos de formação em Educação Física, para que seus objetivos sejam alcançados nos espaços de educação.

Em sentido metafórico, finalizamos: "pés casados. Iniciem a luta...”. Quanto falta para a aliança entre a Luta Marajoara e o currículo? E para seu reconhecimento como conteúdo socialmente relevante? O que mais explica a não valorização de seu conhecimento? Os desafios são muitos. Que essa pesquisa possa fomentar outras, objetivando um lugar para a Luta Marajoara no currículo de formação em Educação Física, tanto regional quanto nacionalmente. Iniciemos a luta!

\section{REFERENCIAS}

ARROYO, Miguel. Currículo: território em disputa. Petrópolis: Vozes, 2011.

BRASIL. Ministério da Educação. Base Nacional Comum Curricular. Brasília, DF, 2018a, Disponível em:

http://basenacionalcomum.mec.gov.br/images/BNCC_EI_EF_110518_versaofinal_site.pdf. Acesso em: 20 mar. 2019.

BRASIL. Ministério da Educação. Diretrizes Curriculares para os Cursos de Graduação. 2000. Disponível em: www.mec.gov.br/sesu/ftp/DocDiretoria.doc. Acesso em: 20 fev. 2019.

BRASIL. Ministério da Educação. Conselho Nacional de Educação. Parecer CNE/CES n 584, de 3 de outubro de 2018. Diretrizes Curriculares Nacionais do curso de graduação em Educação Física. Brasília, DF, 2018b. Disponível em: http://portal.mec.gov.br/docman/outubro-2018-pdf-1/99961pces584-18/file. Acesso em: 12 set. 2019.

BRASIL. Ministério da Educação. Resolução no 2, de 1 de julho de 2015. Diretrizes Curriculares Nacionais para a formação inicial em nível superior (cursos de licenciatura, cursos de Formação pedagógica para graduados e cursos de segunda licenciatura) e para a formação continuada. Brasília, DF, 2015. Disponível em: http://portal.mec.gov.br/docman/agosto-2017-pdf/70431-rescne-cp-002-03072015-pdf/file. Acesso em: 10 ago. 2019. 
BRASIL. Ministério da Educação e Cultura. Secretaria de Educação Fundamental. Parâmetros Curriculares Nacionais: Educação Física. Brasília: MEC/SEF, 1997.

CORREIA, Walter Roberto. Educação Física Escolar: o currículo como oportunidade histórica. Revista Brasileira de Educação Física e Esporte, São Paulo, v. 30, n. 3, p.831-836, set. 2016.

CRUZ, Miguel Evangelista Miranda. Marajó: essa imensidão de ilha. São Paulo: M.E.M. Cruz, 1987.

CURSO DE EDUCAÇÃO FÍSICA. Projeto Político Pedagógico do Curso de Educação Física. Universidade do Estado do Pará. Belém, 2007. Disponível em:

https://paginas.uepa.br/ccbs/edfisica/files/PPP_UEPA.pdf. Acesso em: 13 fev. 2019.

DARIDO, Suraya Cristina. Educação Física na escola: questões e reflexões. Rio de Janeiro: Guanabara Koogan, 2003.

DARIDO, Suraya Cristina; RANGEL, Irene Conceição (coord.). A educação física na escola: implicações para a prática pedagógica. Rio de Janeiro: Guanabara Koogan, 2005.

FREIRE, Paulo. Pedagogia da autonomia: saberes necessários à prática educativa. São Paulo: Paz e Terra, 1996.

GURGEL, Fabio. Brazilian Jiu Jítsu: manual pessoal de jiu-jítsu. Rio de Janeiro: Axcel, 2007.

IORA, Jacob Alfredo; SOUZA, Maristela da Silva; PRIETTO, Adelina Lorensi. A divisão licenciatura/bacharelado no curso de Educação Física: o olhar dos egressos. Movimento, Porto Alegre, v. 23, n. 2, p. 461-474, abr./jun. 2017.

MARCONDES, Nilsen Aparecida; BRISOLA, Elisa Maria. Análise por triangulação de métodos: um referencial para pesquisas qualitativas. Revista Univap, São José dos Campos, v. 20, n. 35, jul. 2014.

MORGAN, David. The Focus Group Guidebook. Thousand Oaks: Sage, 1998.

NASCIMENTO, Paulo Rogério; ALMEIDA, Luciano de. A tematização das lutas na Educação Física Escolar: restrições e possibilidades. Movimento, Porto Alegre, v. 13, n. 3, p. 91-110, set./dez. 2007.

NEIRA, Marcos Garcia (org.). Educação Física cultural: o currículo em ação. São Paulo: Labrador, 2017.

NEIRA, Marcos Garcia. Educação Física cultural: inspiração e prática pedagógica. 1. ed. Jundiaí: Paco, 2018.

NÓVOA, António. Formação de professores e profissão docente. In: NÓVOA, António (coord.).

Os professores e a sua formação. Lisboa: Dom Quixote, 1992. p. 13-33.

PACHECO, José Augusto. Currículo: teoria e práxis. Portugal: Porto Editora, 1996. 
PIMENTA, Selma Garrido. Formação de professores: identidade e saberes da docência. In: PIMENTA, Selma Garrido (org.). Saberes pedagógicos e atividade docente. São Paulo: Cortez Editora, 1999. p. 15-34.

RUFINO, Luiz Gustavo Bonatto; DARIDO, Suraya Cristina. Análise da prática pedagógica das lutas em contextos não formais de ensino. Revista Brasileira de Ciência e Movimento, Brasília, v. 23, n. 1, p. 12-23, 2015.

SACRISTÁN, José Gimeno. Currículo: uma reflexão sobre a prática. 3. ed. Porto Alegre: Artes Médicas, 2000.

SALLES, Vicente. O negro na formação da sociedade paraense: textos reunidos. Belém: PakaTatu, 2004.

SANTOMÉ, Jurjo Torres. As culturas negadas e silenciadas no currículo. In: SILVA, Tomaz Tadeu. Alienígenas na sala de aula. Petrópolis: Vozes, 1995.

SANTOS, Carlos Afonso Ferreira dos; FREITAS, Rogério Gonçalves de. Luta Marajoara e memória: práticas "esquecidas" na educação física escolar em Soure-Marajó. Caderno de Educação Física e Esporte, Marechal Cândido Rondon, v. 16, n. 1, p. 57-67, jan./jun. 2018.

SILVA, Tomaz Tadeu. O currículo como fetiche. 1 ed. Belo horizonte: Autêntica, 2006.

SOARES, Carmen Lucia et al. Metodologia do ensino de Educação Física. São Paulo: Cortez, 2012.

\section{NOTAS DE AUTOR}

\section{AGRADECIMENTOS}

Agradecemos aos sujeitos de nossa pesquisa, docentes, e especialmente discentes, da instituição investigada, pela disponibilidade em colaborar com o manuscrito.

CONTRIBUIÇÃO DE AUTORIA

Não se aplica.

\section{FINANCIAMENTO}

Não se aplica.

\section{CONSENTIMENTO DE USO DE IMAGEM}

Não se aplica.

\section{APROVAÇÃO DE COMITÊ DE ÉTICA EM PESQUISA}

Não se aplica.

\section{CONFLITO DE INTERESSES}

Os autores declaram não haver conflito de interesses. 


\section{LICENÇA DE USO}

Os autores cedem à Motrivivência - ISSN 2175-8042 os direitos exclusivos de primeira publicação, com o trabalho simultaneamente licenciado sob a Licença Creative Commons Attribution Non-Comercial ShareAlike (CC BY-NC SA) 4.0 International. Esta licença permite que terceiros remixem, adaptem e criem a partir do trabalho publicado, desde que para fins não comerciais, atribuindo o devido crédito de autoria e publicação inicial neste periódico desde que adotem a mesma licença, compartilhar igual. Os autores têm autorização para assumir contratos adicionais separadamente, para distribuição não exclusiva da versão do trabalho publicada neste periódico (ex.: publicar em repositório institucional, em site pessoal, publicar uma tradução, ou como capítulo de livro), com reconhecimento de autoria e publicação inicial neste periódico, desde que para fins não comerciais e compartilhar com a mesma licença.

\section{PUBLISHER}

Universidade Federal de Santa Catarina. Programa de Pós-Graduação em Educação Física. LaboMídia - Laboratório e Observatório da Mídia Esportiva. Publicado no Portal de Periódicos UFSC. As ideias expressadas neste artigo são de responsabilidade de seus autores, não

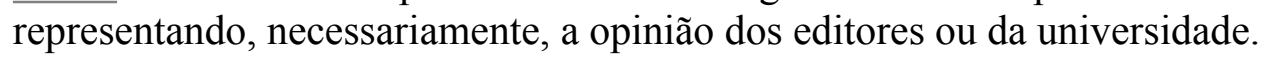

\section{EDITORES}

Mauricio Roberto da Silva, Giovani De Lorenzi Pires, Rogério Santos Pereira.

\section{HISTÓRICO}

Recebido em: 11 de Junho de 2019.

Aprovado em: 19 de Novembro de 2019. 